\title{
A Proteção ao Usuário de Serviço Público no Contexto da Reforma do Estado ${ }^{1}$
}

\section{Yivian Cristina Lima}

Advogada, especialista em Direito Administrativo pelo Instituto Brasileiro de Estudos Juridicos, mestranda em Direito do Estado pela Universidade Federal do Paraná e membro do

Núcleo de Pesquisa em Direito Público do Mercosul da Universidade Federal do Paraná.

\section{Considerações preliminares}

O

Estado Brasileiro vem sofrendo profundas modificações e transformações sociais. Com a crescente reengenharia do Estado, sua reorientação (inclusive em nível constitucional), acabou por impelir a uma discussão jurídica séria e aprofundada a questão da proteção ao usuário de serviço públics.

O processo de reforma do Estado Brasileiro trouxe à baila situaçōes de risco ao cidadão, o qual encontra-se deslocado do foco de atenção governamental e, portanto, mais exposto à sua atuação, o que acarreta a premente necessidade de fixação de parâmetros limitadores da atividade administrativa, voltados à proteção do usuário-cidadão.
O delineamento da amplitude da noção de usuário, o alcance da sua proteção, o ambiente jurídico em que se insere, são questões que urgem serem aprofundadas, dada a sua atualidade e a efetiva e potencial possibilidade de lesão aos cidadãos em face da orientação gerencial conferida à Administração Pública brasileira.

O objeto do presente ensaio cingese à proteção ao usuário de serviço público no contexto de crise do Welfare State e de seus postulados, na crise de legitimidade e na falência do Estado formal-legal, inserida na realidade da transição da Administração Burocrática para um modelo gerencial fundamentado na ideologia neoliberal.

O Estado na sua concepção tradicional, permeado pela idéia do binômio auto-

\footnotetext{
1. Monografia laureada no XIII Congresso Brasileiro de Direito Administrativo com o prêmio Themístocles Brandåo Cavalcanti, em Florianópols, 30 de setembro de 1999.
} 
ridade-liberdade, passou pouco a pouco a ser contestado, em função desse binômio e do impacto de profundas transformações nas esferas econômica, política e social.

Partindo de uma perspectiva histórica percebe-se que a Administração Pública evoluiu ao longo do tempo, através de três modelos básicos (patrimonialista, burocrático e gerencial), sem que seja possível entendê-los como estanques, visto que não foram totalmente abandonados.

A estrutura do Estado na Adminis. tração Patrimonialista funcionava como uma extensão do poder do soberano. A res publica não se diferenciava da res principis. Esse modelo nepotista e autoritário de ad. ministração só cedeu lugar no momento em que se firmaram a democracia e o capitalis. mo, sob a égide do ideário liberal. Nascia o modelo burocrático.

A Administração Burocrática se originou no ambiente do Estado Liberal como estrutura destinada a limitar a ação do Estado, a assegurar a liberdade da burguesia e a mitigar os poderes do soberano, onde se afirmava que a própria sociedade regularia os conflitos sociais através do exercício das potencialidades dos cidadãos. O Estado Liberal foi o propulsor da civilização moderna.

No entanto, os conflitos não se resolveram segundo essa lógica, pelo contrário, se intensificaram, o que acabou por determinar o fracasso da ideologia liberal.

Surge, então, em face de necessidades sociais, uin Poder Público atuante, preccupado com a vida socioeconômica da sociedade que representa, um Estado intervencionista cuja proposta é a realização do desenvolvimento econômico, da dignidade da pessoa humana e do bem-estar social, orientado para um modelo de administração calcado no controle de ineios, no procedimento e na prestação de serviços públicos. Nascia o Estado de Bem-Estar Social ou de Prestações.

Caracterizava-se este pelo intervencionismo nos diversos setores da sociedade, voltado para o bem comum do povo e para a satisfação das necessidades comunitárias.

Porém, o desenvolvimento da sociedade e o crescente aumento nas demandas sociais acabaram por comprometer a qualidade e a efetiva prestação dos serviços, além de ocasionar um agigantamento da máquina administrativa. ${ }^{2} \mathrm{~A}$ ascencão do neoliberalismo e da globalização completaram o quadro de crise do paradigma então norteador da ação administrativa.

$\mathrm{O}$ Estado Social frente à perspectiva de globalização possuía dois caminhos: ou fortalecia o universo estatal para não se subordinar ao domínio dos países centrais ou inseria-se no contexto global de forma su-

2. Bresser Pereira afirma que "na realizaçâo das atividades exclusivas de Estado e principalmente no oferecimento dos serviços sociais de educaçăo e saúde, a administração pủblica burocrática, que se revelara efetiva em combater a corrupçăo e o nepotismo no pequeno Estado Liberal, demonstrava agora ser ineficiente e incapaz de atender com qualidade as demandas dos clientes no grande Estado Social do século XX" (in A Reforma do Estado dos Anos 90: Lógica e Mecanismos de Controle, Brasília, Cadernos do MARE da Reforma do Estado, caderno n01, 1997, p.13). 
bordinada, acompanhando a ideologia do neoliberalismo e reduzindo a soberania. ${ }^{3}$

Neste ponto e acompanhando tendência internacional de reducionismo e redimensionamento das atividades ditas estatais, o Estado brasileiro passou a direcionar os recursos públicos ao custeio de atividades essenciais, retirando-se paulatinamente de setores da sociedade, os quais passam a ser geridos pela iniciativa privada e apenas fiscalizados pelo Poder Público.

A Admit tistração Burocrática do Estado Social (de prestaçōes) fulcrada no procedimento, na seleção legal de pessoal, no trinômio lei, legitimidade e democracia, e no controle efetivo de meios e resultados, reorienta-se para um modelo gerencial de administração, calcado no consenso e na procedimentalidade, na transferência para o setor público não estatal dos serviços sociais e científicos competitivcs, onde os meios nâo são controláveis, apenas importando o alcance do fim destinado.

O Estado pretende não só coordenar e orientar, quando não direcionar, a ati- vidade da iniciativa privada, como também se substituir, em certas áreas estratégicas, à própria iniciativa privada, de forma a controlar e a regular as flutuaçōes da economia capitalista. ${ }^{4}$

Para tanto, diferencia-se interesse público de interesse estatal e reorienta-se a dicotomia público-privado, criando um novo setor na esfera da Administração Pública, o setor público não estatal. ${ }^{5} \mathrm{~A}$ superação dessa dicotomia, Estado-mercado, no entender de ELI DINIZ, exigiu um novo modelo de gestão governamental e um novo padrão de articulação Estado-sociedade. ${ }^{6}$

Há uma nítida tendência de publicizaçăo ${ }^{7}$ no intuito de investir o particular na prestação do serviço público. $\mathrm{O}$ agravante nessa situaçāo é que existe uma diferença considerável de ideologia entre a Administração Pública (que deve visar o bem comum) e o particular (que visa o lucro).

Tal divergência pode resultar numa situação de risco ao cidadão, onde se esquece o universo da cidadania e se privilegia o usuário, o consumidor, aumentando

3. Conforme as liçōes de Paulo Bonavides, a espécie de Estado Social voltada para a humanizaçăo do poder, para fundamentos sociais de liberdade, inspirado na justiça e igualdade, encontra-se ameaçada na conservaçăo de suas bases e conquistas. Esmaecer e destruir tal Estado faz parte das políicas neoliberais adotadas em nome da globalizaçāo e da economia de mercado, "bem como da queda de fronteiras ao capital migratorio, cuja expansảo e circulaçăo sem freio, numa velocidade imprevisível, contribui irremissivelmente para decretar e perpetuar a dependência dos sistemas nacionais, indefesos e desprotegidos (in Do Estado Liberal ao Estado Social, 6. ed., Editora Malheiros, 1996, p. 11).

4. CARRION, Eduardo K.M., in Neoliberalismo e Reforma Constitucional, Edibej, 1998, p.284.

5. Nuria Cunill Grau afirma que "a introdução do 'público' como uma terceira dimensão, que supera a visão dicotômica que enfrenta de maneira abscluta o 'estatal' com o 'privado', está indiscutivelmente vinculada à necessidade de redefinir as relaçöes entre Estado e sociedade". (in La Rearticulación de las Relaciones Estado-Sociedad: en Busqueda de Nuevos Sentidos, Revista del Clad - Reforma y Democracia, $n^{2} 04$, jul./1995, p. 31-32).

6. Crise, Reforma do Estado e Governabilidade, Rio de Janeiro: Ed. Fundação Getúlio Vargas, 1997, p. 197.

7. Transformaçăo de uma organizaçä́o estatal em uma organizaçăo de direito privado, mas pública não-estatal. 
ainda mais o fator de exclusão social no país e beneficiando apenas os indivíduos dotados de poder de consumo.

De outra sorte, também se evidencia forte possibilidade de privatização, a citar como exemplo a situação em que uma autarquia, pessoa jurídica de direito públi. co, após receber a qualificação como orga nização social, se caracteriza como pessoa jurídica de direito privado.

O problema apontado deve ser evitado e controlado pelo Estado e nesse ponto reside outro fator problemático da reforma administrativa, pois ao se retirar da execuçăo de inúmieras atividades, o Estado tem o dever-poder de fiscalizar e controlar a prestação do serviço, o resultado eficiente, ofim a ser alcançado, o que impulsionará o inchaço dos já precários órgãos de controle e possivelmente uma ineficiência estrutural na fiscalização. ${ }^{8}$ Essa é a gênese da reforma administrativa consolidada pelo Governo Federal através da Emenda Constitucional n $19 / 98$. Não se trata de mera redução de dirnensōes estruturais, mas de uma alteração na orientaçāo da gestão da coisa pública, com vistas à transformação do Estado e do aparato da Administração Pública.

Uma reorientação, onde o que se busca é uma nova feição do Estado, não mais burociática, mas predominantemente gerencial. Resta saber se essa nova postura estatal atenderá aos ditames do interesse público e a seus fins.

É notório que a atual conjuntura política e econômica impõe referida mudança, onde o Estado deve permitir o desenvolvimento de atividades públicas por entes privados, no intuito da implementação da eficiêr.cia no serviço público.

A situação é preocupante pois percebe-se claramente o intuito de flexibilização da atuação da Administração e em especial do procedimento administrativo, o que fatalmente implica em ameaça ao cidadão, o qual vê suprimidas etapas procedimentais e a possibilidade de impugnação fase a fase em face de eventual lesão, com violaçāo a direitos fundamentais.

É evidente o risco ao cidadão 9 e o prejuízo na sua defesa contra atos que importem em danos, no exercício do seu direito constitucional ao contraditórin. nois só poderá insurgir-se contra o resultado do procedimento, estando impossibilitado de atacar o ato danoso quando da sua incidência.

O que se observa atualmente é uma crescente manifestação no sentido de agilizar os procedimentos administrativos,

8. Juarez Freitas de forma esclarecedora alerta para a inevitável alteraçăo de paradigma e para o necessário aprimoramento dos meios de controle, afirmando que "a reestruturação do Estado deve ser feita com extremo cuidado, pois, se é certo que devemos avançar rumo a paradigmas novos e eticizantes, não é menos aconselhável fazê-lo de molde a inovar sem prejuizo das estruturas controladoras que carecem de reforço e aperfeiçoamento, não de serem dissolvidas... Não ficaremos entregues tampouco a controles exclusivos de resultados, porém, submeteremos os resultados ao controle efetuado em face das diretrizes constitucionais (in O Controle dos Atos Administrativos e os Princípios Fundamentais, São Paulo: Malheiros, 1997, p.16-17).

9. Opróprio Governo Federal expőe o risco mencionado, quando afirma que o resultado da reforma será um Estado mais eficiente, menos voltado à proteção e mais à promoçăo da capacidade de competiçáo (PEREIRA, Bresser, op. cit., p. 52). 
implantando-se para tanto o modelo gerencial.

A busca da manutenção e o respeito ao núcleo de direitos fundamentais fulcrados no cidadão desde o Estado Liberal e presentes ainda no Estado Social devem ser a tônica da dita reengenharia do Estado brasileiro.

A proteção ao usuário de serviço público tanto no contexto liberal, como no Estado Social ou na ascensão da ideologia neoliberal deve priorizar a existência digna dos cidadãos, com a satisfação de suas necessidades essenciais.

A Constituição Brasileira impõe tal proteção, quando em sua dogmática principiológica, emancipatória e personalizadora prioriza os direitos fundamentais do cidadão, inclusive contra particulares.

Indaga-se quão reducionista deve ser o Estado brasileiro, e qual será seu papel e sua responsabilidade frente às Entidades Privadas encar regaủas cia execuçàu ciu serviço público. Perquire-se ainda quais serão as atividades suscetíveis de atribuição à atuação dos particulares e quais aquelas que pela sua própria natureza não o poderão ser.

OEstado Brasileiro adotou constitucionalmente essa postura reducionista através da reforma administrativa introduzida pela Emenda no 19/98 à Carta Política vigente, o que acabou por ressaltar a importância da definição da proteção ao usuário do aludido serviço.
Nessa linha, a Lei de Concessões delimitou direitos dos usuários, salientando a necessidade de proteção e orientando a análise da atividade estatal equiparada a de um fornecedor de serviços (direta ou indiretamente).

Questão de suma importância neste ambiente é a prestação de serviço público de modo eficiente, com maximização da eficácia estatal, afirmando-se a equivalência da posição do usuário de serviço público à do consumidor de serviços ou produtos, com as conseqüências daí decorrentes.

Nãose pode olvidar que em face dessa postura de fornecedor, o Poder Público fica submetido de igual modo ao elenco das garantias conquistadas com o advento do Código do Consumidor, até porque os direitos apontados no texto da referida lei não excluem tais garantias.

Impende considerar que a referida proteção vincula-se também ao direito de participação política do cidadão, o quai para coibir abusos e fiscalizar a prestação do serviço detém inúmeros instrumentos (legislativos, administrativos e judiciais) de atuação, conforme apontadio por DIOGO DE FIGUEIREDO MOREIRA NETO. ${ }^{10}$

A proteção dos usuários de serviço público constitui atualmente tema de grande relevância na área do Direito Público, em especial Direito Administrativo e Constitucional, pelo avançado processo de privatizações desencadeado pelo Governo Federal e pela necessária atuação do Estado senão como o agente executor do servi-

10. Direito da Participaçāo Politica. Rio de Janeiro: Renovar, 1992, p. 81 e ss. 
ço, então como o ente regulador e fiscalizador da atividade, em face da ausência de transferência da titularidade do interesse público envolvido para o particular.

Essa situação se impõe pelo postulado criado pelo welfare state e mantido pelo Estado neoliberal de que o serviço público não é e não pode ser renunciado, dada a sua natureza e a sua vinculação ao interesse público. Apenas a sua execução é que pode ser delegada a entes privados por contrato ou realizada por órgãos da Administraçāo direta ou indireta.

Neste quadro de reengenharia estatal torna-se necessário implantar instrumentos de proteção ao usuário de serviço público, ao "cidadão cliente", para assegurar que os serviços prestados realmente produzam o resultado eficiente esperado pela lógica neoliberal da reforma administrativa efetivada no Brasil.

O cidadão deve ser protegido pelo ordenamento jurídico en face da ameaça de restrição de suas garantias fundamentais, constitucionalmente estatuídas, como por exemplo a mitigação do contraditório no processo de tomada de decisão dentro do procedimento administrativo.

Não resta dúvida de que o contexto mundial se alterou, porém é necessário compatibilizar a eficiência com o humanismo, com a defesa dos postulados constitucionais, construindo um discurso alternativo ao neoliberalismo, calcado no homem, na dignidade da pessoa humana ${ }^{11}$ e nos direitos fundamentais, e não apenas na lógica do mercado.

Deve-se verificar a afetação e amplitude da proteção ao cidadão frente à reforma neoliberal introduzida pela Emenda Constitucional $n^{\circ} 19 / 98$ e identificar uma possibilidade de readequação do Estado Social frente ao posiulado da eficiência, não só ligada à competência estatal, mas também a legitimidade dos fins que se pretende alcançar por meio da ação governamental.

\section{0 ambiente da reforma do estado e a proteção ao usuário de serviço público}

Sob o impacto de consideráveis alterações nas esferas econômica, política e social, a concepção tradicional de Estado poucc a pouco passou a ser contestada.

A nossa sociedade vivencia a chamada crise de paradigmas. Num primeiro momento vivemos sob a égide do paradigma do Estado Liberal, o qual deu lugar ao paradigma do Estado Social, atualmente em crise em face do contumaz aumento de demandas sociais e da deficiência do Poder Público em atendê-las.

\footnotetext{
11. Carmen Lúcia Antunes Rocha afirma que é "o reconhecimento e garantia da dignidade humana que se projeta na ordem juridica a legitimá-la e orientá-la no atendimento dos cbjetivos tundamentais da sociedade" (in Cidadania e Constituição - as Cores da Revoluçăo Constitucional do Cidadão, Revista da $\mathrm{OAB}$, ano XXVII, n²65, p. 51).
} 
Instaurada a crise do paradigma de Estado Providência ${ }^{12}$ e de seus institutos, ascendeu no ideário político da reforma a ideologia neoliberal, afirmando a sobrecarga estatal em face das necessidades sociais, a ineficiência da burocracia baseada no controle formal e a conseqüente redução do aparelho do Estado.

É a efetivação de um processo de mundialização da economia, com uma reiterada fuga do Direito Administrativo para o Direito Privado, onde o Estado trata de demitir-se das funções que assumiu, entregando-as ao setor privado. ${ }^{13}$

No entanto, cabe ressaltar que a redução das dimensões estatais não constitui apenas mera diminuição das atividades regidas diretamente pelo Poder Público, mas deve significar alteração na qualidade do serviço prestado, importando tal mudança em continuidade, eficiência, adequabilidade e respeito ao ustário do serviço público.

A lex mercatória surge como direito paralelo ao direito do Estado, num processo de desconstitucionalização, de criação de equivalentes normativos, de flexibilização, de desregulamentação e de privatização em sentido lato. ${ }^{14}$
A ideologia da reforma do Estado se aproxima da verdade da economia, do princípio da eficiência, o qual pode apresentarse muito negativo pela determinação de controle somente pelo resultado.

Este é o ambiente sociopolítico atual do mundo ocidental, e o Brasil buscou a inserção neste contexto de forma subordinada, com relativização de soberania. $\mathrm{O}$ centro das atenções do Estado não é mais o homem, o cidadão, mas sim o mercado e a credibilidade internacional.

O referido quadro além de inevitável é extremamente perigoso, pois a ausência de preocupação com o processo de tomada de decisão (importando somente em controle a posteriori) e a orientação da administração da coisa pública para o lucro, podem gerar graves violações ao núcleo de direitos fundamentais do cidadão.

\section{Os componentes da reforma} consubstanciam-se na redução do tamanho do Estado e do grau de sua interferência, no aumento da governança ${ }_{i}{ }^{15}$ na ênfase do controle via contrato de gestão e na visão do cidadão como cliente do Estado, no potencial do usuário como consumidor.

12. Bresser Pereira afirma que a crise constitui-se fundamentalmente de dois aspectos, um relacionado com a crise fiscal do Estado e outro com a forma de intervençăo do Estado na economia, segundo ele, burocrática e planejadora. (in O Estado e a Ordem Económica, Anais do Ciclo de Estudos da Reforma Constitucional de 1995, Rio de Janeiro, p. 65 e 67).

13. João Luiz Duboc Pinaud (in Globalizaçāo: Estado e Empresa Pública, publicado no livoo Globalizaçáo, Neoliberalismo e o Mundo do Trabalho, Edibej, 1998, p. 293) assinala que "a globalizaçăo, com as privatizaçöes que sua agenda necessita, é uma nova Pax Romana, conquistando e saqueando a título de internacionalizar e equilibrar. É uma construçāo jurídico-política sofisticada, nova retórica dos imperialismos modernos. E sua new-face de dominação mediante ordem económica internacional nắc esconde que é necessário softer o governo dos mais fortes e deixar ao seu arbítrio dar ou tomar o que quiserem, sem outros juizes que eles mesmos".

14. Desnacionalizaçăo, reduçáo do intervencionismo econômico, flexibilizaçăo dos monopólios.

15. É a capacidade governativa, em sentido amplo, que abrange a capacidade do Poder Público naimplementaçăo das politicas e na consecuçăo das metas coletivas. Segundo Bresser Pereira, o Estado só tem governança quando possui condiçōes financeiras e administrativas para transformar em realidade as decisōes que toma. Em năo havendo tais condiçōes existe apenas governo, mas nâo governança (op. cit., p.40). 
A proteção ao usuário de serviço públicc está diretamente ligada ao conceito de cidadania, o qual por imperatividade constitucional não pode ser restringido. A proteção deve ser para todos, independentemente de poder econômico.

Nesse sentido, CARMEN LÚCIA ANTUNES ROCHA afirma que a cidadania é uma das formas de manifestaçâo da liberdade sociopolítica, elabora-se para por à mostra a dignidade do homem em sua experiência com o outro. ${ }^{16}$

A consciência da exigibilidade de qualidade está ínsita ao revitalizamento do serviço público e à própria condição do usuário.

Nessa esteira, não há como não identificar os direitos dos usuários com aqueles pertencentes aos consumidores em geral. Em ambos os casos o enfoque primário é comum: a consciência da cidadania para exigir serviço de qualidade e eficiente e/ou produto de qualidade, seja decorrente de atividade particular on de atividade vinculada ao serviço público.

O Estado Democrático de Direito traz em seu bojo a prevalência de princípios vetores, tais como a igualdade, a legalidade, a impessoalidade, a probidade administrativa, a responsabilidade civil do Estado, a moralidade, a isonomia, a eficiência, etc. Assim, a própria ideologia do Estado brasileiro impõe a devida proteçāo ao usuário de serviço público, como a impõe ao consumidor comum.
A prestação do serviço por entes privados deve ser entendida como uma delegação do Poder Público, o qual conserva, entretanto, a titularidade do serviço (que não pode ser renunciada, como já mencionado) e portanto, a obrigação de fiscalizar, assegurar o resultado e responder pela atividade.

\section{As diretrizes constantes do ordenamento jurídico}

O sistema jurídico normativo permite uma análise verticalizada e aprofundada sobre a questão, apontando o caminho para a realização de um Estado necessário, que se utiliza da iniciativa privada para a consecução do serviço público, mas que preserva os direitos humanos fundamentais e zela pela manutenção do cidadão como o enfoque primordial.

E nesse sentido a Carta Política se orienta, determinando a prestação de serviços públicos diretamente ou sob o regime de concessão, precedida de licitação, prevendo a regulação por lei dos direitos dos usuários (art. 175, caput e parágrafo único, inciso II).

$\mathrm{Na}$ mesma linha determina a eficiência nas atividades ligadas ao interesse público (art. 37, caput), a participação do usuário na Administração direta e indireta, o direito a reclamações quanto ao serviço, assegurada a manutenção e avaliação periódica da qualidade e desempenho do mesmo, bem como o acesso dos usuários a

16. Op. cit, p. 49. 
registros administrativos e representação contra exercício negligente (art. 37, $\S 3^{\circ} \mathrm{e}$ incisos).

Ao lado de disposições dessa grandeza, impõe tanto a pessoas jurídicas de direito público como também de direito privado, prestadoras de serviço público, a responsabilidade objetiva por danos causados por seus agentes, demonstrando claramente a opção do legislador constituinte em conceder proteção aos usuários de serviço público, em caráter geral.

De igual modo, a Lei de Concessões Públicas (Lei n⿳⺈ 8.987/95), traz em seu conteúdo dispositivos que visam proteger o usuário, determinando a prestação de serviço adequado, regular, contínuo, eficiente, atual e módico (art. 6º e $\S \S$ ), direitos e deveres dos usuários sem prejuízos daqueles decorrentes da Lei $\mathrm{n}^{\circ} \mathbf{8 . 0 7 8 / 9 0}$ (art. $7^{\circ} \mathrm{e}$ incisos), responsabilidade da concessionária e prestação de contas ao usuário (arts. 25 e 31), etc.

Ainda resta aduzir a relevância das disposições contidas na referida Lei $\mathrm{n}$ o 8.078/90 (Código do Consumidor), em face da identidade de consciência entre o usuário de serviço público e do consumidor comum.

Cláusulas que definem a figura do fornecedor (art. $3^{\circ}$, caput) e a sua responsabilidade objetiva (art. 14, caput), a racionalização e melhoria dos serviços públicos (art. $4^{\circ}$, inciso II), a sua adequada e eficaz execução (art. 6º , inciso X), por evidente têm extensão reconhecida frente à prestação de serviços públicos, disciplinando a matéria.

No tocante a esse particular, as disposições que guardan incompatibilidade com o princípio da supremacia do interesse público sobre o particular devem ser interpretadas à luz do princípio da primazia da defesa do usuário de serviço público, de forma teleológica.

Assim, a investigação jurídica acerca da problemática da proteção ao usuário de serviço público não pode se esquivar à análise dos diplomas legais citados, bem como isentar-se de abordar os sintomas políticos e sociais que redundaram na tendência reducionista do Estado, na delegação de atividades e no dever de fiscalizar e assegurar a execução do serviço.

Em síntese, a adoção de um novo paradigma para o Estado implica no repensar a reforma não só pela ótica neoliberal ou tecnocrática, mas priorizar a importância de uma acão governamental para preencher as lacunas existentes e levar o mercado a funcionar de forma eficiente, em consonância com um projeto coletivo de satisfação das necessidades comunitárias e fulcrada na justiça social, conforme determina a Carta Magna Federal. ${ }^{17}$

Justifica-se pela importância de um estudo voltado para a tutela dos valores fundamentais condicionantes do sistema normativo e para a elaboração de um discurso racional alternativo à legitimação pelo

17. Artigo 170 - "A ordem econômica, fundada na valorizaçäo do trabalho humano e na live iniciativa, tem por fim assegurar a todos existência digna, conforme os ditames da justiça social.' 
resultado eficiente, visando recompor a feição do Estado através de uma socialização moderada, no intuito de se alcançar um liberalismo mais adequado ao conteúdo do Direito e da Justiça, com a preservaçăo das conquistas do Welfare State.

\section{Conclusões}

A. reforma dos Estado dos anos 90 pressupõe cidadãos menos protegidos ou tutelados pelo Estado, porém mais livres para desenvolver-se, conforme entende LUIZ CARLOS BRESSER PEREIRA. ${ }^{18}$ Essa é a filosofia da política neoliberal adotada pelo Governo Federal a partir da Emenda Constitucional n 19/98.

Tal sistema apresenta-se por demais conveniente para os detentores do poder, pois outorga poder de controle e fiscalização ao usuário, ao cidadão, o qual encontra-se, na sua maioria, inserido na realidade brasileira intelectualmente despreparado, marginalizado e excluído do processo de conhecimento.

A uma primeira análise poder-se-ia afirmar que o grande sujeito de direito do novo Estado neoliberal é o "cidadão-usuário", em vista do enfoque dado à sua parti- cipação política. No entanto, ao se aprofundar a questão percebe-se que a mola propulsora da reforma é o mercado, e que o referencia! de toda essa engrenagem não é o cidadão, mas o "cliente-consumidor".

Não se fazem necessárias maiores consideraçōes para se constatar que a política reformadora acarreta maior desigualdade social, ${ }^{19}$ pois alija da discussão política acerca da qualidade da prestação do serviço público e da sua destinação aquele cidadão carecedor de poder aquisitivo ou de potencial consumidor, marginalizando-o ainda mais.

A necessidade de adoção de novas perspectivas para o Estado levou ao desmonte do Estado brasileiro, com reformas que violam direitos fundamentais dos indivíduos e suprimem parte de sua cidadania.

$O$ postulado da eficiência, em que pese seus efeitos positivos, ${ }^{20}$ possibilita uma fuga aos meios de contrcle e uma queima de etapas no procedimento que ameaçam o núcleo de direitos fundamentais do cidadão instituídos no texto da Carta Míagna (impessoalidade, contraditório, etc.) e com isso acarretam a falca de transparência no trato da res publica, de orientação finalística para o resultado.

18. Op. cit, p. 53.

19. Nesse sentido Paulo Bonavides afirma que "basta ver que a adoção do neoliberaísmo na sociedade brasileira pelo Governo, em beneficio unicamente de parcelas privilegiadas do meio financeiro e empresarial, tem gerado na crdem social efeitos catastrófios: duma parte, empobrece o povo, sobretudo as classes assalariadas, conduzindo ao mesmo a juventude para a senzala do xime e da prostituiçăo. E por essa estrada vai igualmente inaugurando novos cativeiros, desagregando valores, cavando abismos, sepultando aspiraçôes, estiolando esperanças, desfigurando, enfim, o semblante nacional das instituiçoes" (op. cit., p. 19).

20. Direcionamento da atividade e dos serviços públicos à efeividade do bem comum, imparcialidade, neutralidade, participaçáo e aproximaçáo dos serviços da populaçăo, desburocratização, etc., conforme leciona Alexandre de Moraes, in Reforma Administrativa, 2. ed., Săo Paulo: Atlas, 1999, p. 30-34. 
Nessa lógica, a proteção dos usuários de serviços públicos deve ser encarada não sob o prisma das razões do Estado, mas voltada a proteger os valores fundamentais do cidadão e a garantir a sua existência digna.

Deverá necessariamente tratar do aperfeiçoamento do serviço, da participaçāo do usuário na Administração direta e indireta, da avaliação periódica da qualidade do serviço com conseqüente responsabilidade para o administrador, da fiscalização do Estado e da sociedade.

Todos estes aspectos aliados a diplomas legais como o Código do Consumidor e à instituição da responsabilidade civil do Estado, constituem os ingredientes necessários para o desenvolvimento social e democrático do Estado brasileiro enquanto nação politicamente organizada, rumo a uma definitiva, sólida e justa proteção aos usuários de serviço público.

Tais questões sem dúvida devem ser suscitadas e analisadas de forma aprofundada no intuito do aprimoramento do conceito de Estado necessário, nem mínimo, nem máximo, fulcrado na manutenção das liberdades e garantias fundamentais do cidadão e em políticas de bem-estar social. $^{21}$

\section{Bibliografia}

AGUILLAR, Fernando Herren. Controle Social de Serviços Públicos. São Paulo: Max Limonad,
1999.

AMARAL FILHO, Marcos Jordão Teixeira do. Privatização no Estado Contemporâneo. São Pau. lo: Ícone, 1996.

ARAÚJO, Aloízio Gonzaga de Andrade. O Brasil e o Mundo Globalizado. Brasília: Revista da Ordem dos Advogados do Brasil, ano XXVII, $n^{\circ}$ 65, jul./ dez. 1997.

ARRUDA JUNIOR, Edmundo Lima de. Alienaçãoe e Emancipação. Artigo publicado no livro Globalização, Neoliberalismo e o Mundo dc Tra. balho. Curitiba: EDIBEJ, 1998.

ATALIBA, Geraldo e MACHADO, Luiz Alberto. Iniciativa Privada e Serviços Públicos. Curitiba, Se. parata da Revista de Direito Público (Instituto Internacional de Direito Público e Empresarial), vol. 98, 1991.

AZEVEDO, Eurico de Andrade e ALENCAR, Ma. ria Lúcia Mazzei de. Concessão de Serviços Públicos (Comentários às Leis 8.987 e 9.074 - Parte Geral -, com as modificaçōes introduzidas pela Lei 9.648 de 27.05.1998). São Paulo: Malheiros, 1998.

BACACORZO, Gustavo. Visão Atual do Pensamento e Ação Político-Administrativa. Curitiba: Genesis - Revista de Direito Administrativo Aplicado, $\mathrm{n}^{\circ} 09,1996$.

BACELLAK FiLHO, Romeu Felipe. Yrincípios Cons. titucionais do Processo Administrativo Disciplinar. São Paulo: Max Limonad, 1998.

BARACHO, José Alfredo de Oliveira. O Enriquecimento Injusto como Princípio Geral do Direito Administrativo. Rio de Janeiro: Revista de Direito Administrativo, n²10, out./dez. 1997.

- Teoria Geral da Cidadania - A Plenitude da Cidadania e as Garantias Constitucionais e Processuais. São Paulo: Saraiva, 1995.

. O princípio de Subsidiariedade Conceito e Evolução. Rio de Janeiro: Forense, 1997.

21. Atualmente a política de bem-estar social encontra-se comprometida pela redução da presença do Estado nas áreas sociais, pela proposta de rentabilização de certos serviços públicos tradicionalmente deficitários, e por isso mesmo sociais (CARRION, Eduardo K. M., op. cit., p. 286). 
BARCELONA, Pietro. OEgoísmo Maduro e a Insensatez do Capital. São Paulo: Ícone, 1995.

BiELSA, Rafael. Derecho Administrativo. Buenos Aires: La Ley, 1965.

BOBBIO, Norberto. Direito e Estado no Pensamento de Emanuel Kant. 4. ed., Brasília: UnB, 1997.

BONAVIDES, Paulo. Do Estado Liberal ao Estado Social. 6. ed., São Paulo: Malheiros, 1996.

CAETANO, Marcelo. Manual de Direito Administrativo. 10. ed., Cuimbra: Livraria Almedina, tomo l, 1991

Princípios Fundamentais do Direito Administrativo. Rio de Janeiro: Forense, 1989.

CANOTILHO, José Joaquim Gomes. Constituiçāo Dirigente e Vinculação do Legislador - Contributo para a Compreensāo das Normas Constitucionais Programáticas. Coimbra: Coimbra Ltda., 1994.

CARDOSO, Fernando Henrique. Plano Diretor da Reforma do Aparato do Estado. Brasília, Ministério da Administração e Reforma do Estado, 1995.

CARRION, Eduardo K. M. Neoliberalismo e Reforma Constitucional. Curitiba, artigo publicado no livro Globalização, Neoliberalismo e o Mundo do Trabaiho. Curitiba: EDIBEJ, 1998.

CASSAGNE, Juan Carlos. Derecho Administrativo. 5. ed., Buencs Aires: Abeledo Perret, tomo II, 1996.

CASTRO, Claudio Henrique de. A Proteçāo dos Usuários de Serviço Público e a Reforma Administrativa. Revista do Tribunal de Contas do Estado do Paraná, n² 127, 1998.

CASTRO, Paulo Rabello de. A Reengenharia do Estado Brasileiro: Rumo ao Sociocapitalismo. São Paulo, artigo publicado no livro A Reengenharia do Estado Brasileiro. Revista dos Tribunais, 1995.

CHIARINI, Rosalba. La Pubblica Amministrazione Italiana Tra Crisi e Transizione. Giuffrè Editore, Quaderni di Scienza Politica, Rivista Quadrimensale, anno Vl, n²01, aprile/1999.

CLÈVE, Clémerson Merlin. Elementos para um Discurso de Conceituação do Direito Administrativo. 1. ed., São Paulo: Julex Livros, 1988.
CORREAS, Oscar. El Neoliberalismo en el Imaginario Juridico. Curitiba, artigo publicado no livro Direito e Neoliberalismo - Elementos para uma Leiura Interdisciplinar, EDIBEJ, 1996.

COUTINHO, Jacinto Nelson de Miranda. Jurisdiçāo, Psicanálise e o Mundo Neoliberal. Curitiba, artigo publicado no livro Direito e Neoliberalismo - Elementos para uma Leitura Interdisciplinar. EDIBEJ, 1996.

- Atividade Legislativa do Poder Executivo no Estado Contemporâneo e na Constituição de 1988. São Paulo: Revista dos Tribunais, 1993.

CUNILl GRAU, Nuria. La Rearticulación de las Relaciones Estado - Sociedad: en Busqueda de Nuevos Sentidos. Revista del Clad - Reforma y Democracia, $\mathrm{n}^{2}$ 04, jul./1995.

CUNHA JUNIOR, Dirley. A Disciplina Jurídico Constitucional do Desenvolvimento Econômico e do Bem-Estar Social numa Ótica Globalizante, Edição Especial, Salvador, Revista dos Mestrandos em Direito Econômico da Universidade Federal da Bahia, vol. 06, jan. a dez./1998.

DIAS, Eduardo Rocha. Sançōes Administrativas Aplicáveis a Licitantes e Contratados. São Paulo: Dialética, 1997.

DINI!Z, E!i. Crise, Reforma do Estadc e Governabilidade. Rio de Janeiro: Fundação Getúlio Vargas, 1997.

DI PIETRO, Maria Sylvia Zanella. Direito Administrativo. 5. ed., São Paulo: Atlas, 1994.

. Parcerias na Administração Pública. 2. ed., São Paulo: Atlas, 1997.

DIREITO, Carlos Alberto Menezes. Breves notas sobre o primado da Constituição. Rio de Janeiro: Renovar, Revista de Direito Administrativo, $\mathrm{n}^{\mathrm{O}}$ 209, jul./set. 1997.

DROMI, Roberto. Derecho Administrativo. 6. ed. Buenos Aires: Ediciones Ciudad Argentina, 1997.

DROMI, Roberto e MENEM, Carlos. Reforma del Estado. Buenos Aires: Ediciones Ciudad Argentina, 1997. 
DUGUIT, León. Las Transformaciones del Derecho (Públicoy Privado). Buenos Aires: Heliasta, 1975.

DUTRA, Pedro Paulo de Almeida. Controle de Empresas Estatais - Uma Proposta de Mudança. São Paulo: Saraiva, 1991.

FARIAS, Edilsom. Direitos Fundamentais e Políticas Neoliberais. Curitiba, Revista da Faculdade de Direito da Universidade Federal do Paraná, ano $30, n^{\circ} 30,1998$.

FERNANDEZ, Tomás Ramón. Serviços Públicos $e$ Empresas Privadas. Sāo Paulo, Scparata da Revista de Direito Público, vol. 98, abr/jun. 1991.

FERREIRA FILHO, Manuel Gonçalves. Poder Constituinte e Direito Adquirido. Rio de Janeiro: Renovar, Revista de Direito Administrativo, $\mathrm{n}^{\circ} 210$, out./dez. 1997.

Direitos Humanos Fundamentais.

3. ed., São Paulo: Saraiva, 1999.

FIGUEIREDO, Lúcia Valle. Curso de Direito Administrativo. 2. ed., São Paulo: Malheiros, 1995.

. Controle da Administração Públi.

ca. São Paulo: Revista dos Tribunais, 1991.

FREITAS, Juarez. Controle dos Atos Administrativos. Săo Paulo: Malheiros, 1997.

- Estudos de Direito Administrati4n. 7. ed., São Paulo: Malheiros, 1997

- A Proteção do Consumidor de serviços Públicos e o Novo Regime em Face da Emenda Constitucional $n^{\circ}$ 19/98. Informativo de Licitações e Contratos, $\mathrm{n}$ 을 53 , seção doutrina/ parecer, jul./1998

GASPARINI, Diógenes. Direito Administrativo. 4.ed., São Paulo, 1995.

GORDILlO, Agustín. Tratado de Derecho Administrativo - La Defensa del Usuário y del Administrado. 3. ed., Buenos Aires: Fundación de Derecho Administrativo, tomo 2, 1998.

- Después de la Reforma del Estado. Buenos Aires: Fundación de Derecho Ad. ministrativo, 1996.

GRECCO, Carlos M. e MUÑOZ, Guillermo A. La Precariedad en los Permisos, Autorizaciones, Licencias y Concesiones (Aplicación en los Actos y Con- tratos Administrativos en el Orden Nacional, Provincial y Municipal). Buenos Aires: Depalma, 1992.

HABERMAS, Jünger. La Crisis del Estado de Bienestar y el Agotamiento de las Energías Utópicas. Em Ensayos Foliticos, Barcelona: Ediciones Península, 1994.

HAURIOU, Maurice. Précis de Droit Administratif. 12. ed., 1933.

HERNANDO NIETO, Eduarde. La Teuria de La Justicia al Liberalismo político: John Rawls y el Fracaso de La Justicia Procedimental. Lima, Revista da Faculdade de Direito do Peru, nº 50 , dez./1996.

JÈzE, Gaston. Principios Generales del Derecho Administrativo. Buenos Aires: Depalma, vol. 01, 1948.

JUSTEN FILHO, Marçal. Concessōes de Serviços Públicos (Comentários às Leis $n^{9} 8.987$ e 9.074, de 1995). São Paulo: Dialética, 1997.

- Comentários à Lei de Licitações e Contratos Administrativos. Rio de Janeiro: Aide, 1993.

KLIKSBERG, Bernardo. Como transformar o Estado - Para Além de Mitos e Dogmas. Brasília: ENAP, 1992.

LAMOUNIER, Bolivar. Agenda Mínima para a Reforma Polutico - Institucionai. Säo Fauio, artigo publicado no livro A Reengenharia do Estado Brasileiro, Revista dos Tribunais, 1995.

LANDI, Guido e POTENZA, Giuseppe. Manuale di Diritto Amministrativo. 10. ed., Milão: Giuffrè, 1997.

LAUBADÈRE, André de. Direito Público Econômico. Coimbra: Almedina, 1985.

LEAL, Rogério Costa. Hermenêutica e Direito - Consideraçōes sobre Teoria do Direito e os Operadores Jurídicos. Rio Grande do Sul: EDUNISO, 1999.

LEITE, Eduardo de Oliveira. A Monografia Jurídica. 3. ed., São Paulo: Revista dos Tribunais, 1997.

LEMOS, Bruno Espiñeira. O Cenário Global e Uma Análise Crítica acerca do Processo de Desestatização Brasileiro. EdiçãoEspecial, Salvador, Revista dos Mestrandos em Direito Econô- 
mico da Universidade Federal da Bahia, vol. 06, jan. a dez./1998.

LIMA, Ruy Cirne. Princípios de Direito Administrativo. 6. ed., São Paulo: Revista dos Tribunais, 1987.

LOPES, Emâni Rodrigues. Economia e Sociedade face à Globalização. São Paulo, artigo publicado no livro A Reengenharia do Estado Brasileiro, Revista dos Tribunais, 1995.

LOPES, Mauricio Antonio Ribeiro. Comentários à Reforma Administrativa (De acordo com as Emendas Constitucionais 18 de 05.02.1998 e 19 de 04.06.1998) São Paulo: Revista dos Tribunais, 1998.

MARCELINO, Gileno. Govemo, Imagem e Sociedade. Brasília: Funcep, 1988.

MEDAUUAR, Odete. Direito Administrativo Moderno. 3. ed., São Paulo: Revista dos Tribunais, 1999. - Concessão de Serviço Público. São Paulo: Revista dos Tribunais, 1995.

MEIRELLES, Hely Lopes. Direito Administrativo Btasileiro. 12. ed., São Paulo: Revista dos Tribunais, 1986.

MELLO, Celso Antônio Bandeira de. Curso de Direito Administrativo. 10. ed., São Paulo: Malheiros, 1998.

. Serviço Público e Poder de Polícia: Concessãu e Déugurãu. Revista Triniêsial de Direito Público, n² 20.

- Prestação de Serviços Públicos e Administração Indireta. 2. ed., $2^{\mathrm{a}}$ tiragem, São Paulo: Revista dos Tribunais, 1983.

.OPrincípio do Enriquecimento Sem Causa em Direito Administrativo. Rio de Janeiro: Renovar, Revista de Direito Administrativo, $\mathrm{n}^{2}$ 210, out./dez. 1997.

. Discricionariedadee Controle Jurisdi-

cional. 2. ed., São Paulo: Malheiros, 1998.

MELLO, Magno Antonio Correia de. Burocracia, Modemidade e Reforma Administrativa. 1. ed., Brasília: Brasilia Jurídica, 1996.

MODESTO, Paulo. Controle Jurídico do Comportamento Ético da Administração Pública no Brasil. Rio de Janeiro: Renovar, Revista de Direito Administrativo, no 209, jul./set. 1997.
- Reforma do Marco Legal do Ter. ceiro Setor no Brasil. Revista Interessc Público I, jan./mar. 1999.

- Reforma Administrativa e Direito Adquirido. Rio de Janeiro, Revista de Direito Administrativo, $\mathrm{n}^{2} 211$, jan./mar. 1998.

MORAES, Alexandre de. Reforma Administrativa. 2. ed., São Paulo: Atlas, 1999.

MOREIRA NETO, Diogo de Figueiredo. Direito de Participação Política: Legislativa, Administrativa, Juaicial. Rio de Janeiro: Renovar, 1992.

. Cocrdenação Gerencial na Administração Pública. Salvador, Exposição no Seminário A Emenda Constitucional da Reforma Administrativa da Escola Superior de Advocacia Orlando Gomes, 1998.

. O Estado e o Futuro: Prospectiva sobre Aspectos da Instituição Estatal. São Paulo, artigo publicado no livro A Reengenharia do Estado Brasileiro, Revista dos Tribunais, 1995.

OLIVEIRA, João Batista de Araújo e. Desburocratização e Democracia. Campinas: Papirus, 1984.

OlIVEIRA, José Carlos de. Concessōes e Permissões de Serviços Públicos (Serviços Públicos da União, Estados, Municípios e Entes Reguladores). São Paulo: Edipro, 1996.

PEREIRA, Luiz Carlos Bresser. A Reforma do Estado dos Anos 90: Lógica e Mecanismos de Controle. Brasília/DF, Cadernos do MARE da Reforma do Estado, n01, 1997.

- Propostas do Governo para a Reforma do Estado. Rio de Janeiro, Anais do Ciclo de Estudos da Reforma Constitucional de 1995 O Estado e a Ordem Econômica, 1995.

PINTO, João Augusto de Oliveira. A Responsabilidade Civil do Estado - Fornecedor de Serviços anteo Usuário - Consumidor. Belo Horizonte: Ediçōes Ciência Jurídica, 1997.

PORTO NETO, Benedito. Concessão de Serviço Público no Regime da Lei n 8.987/95 (Conceitos e Princípios). São Paulo: Malheiros, 1998.

RAMOS FILHO, Wilson. Direito Pós-Modemo: Caos Criativo e Neoliberalismo. Curitiba, artigo publicado no livro Direito e Neoliberalismo - Elementos para uma Leitura Interdisciplinar. EDIBE], 1996. 
RAMIREZ, Manuel. La Participación Politica. Madrid: Tecnos, 1993.

RIVERO, Jean. Direito Administrativo. Coimbra: Almedina, 1981.

ROCHA, Carmen Lúcia Antunes. Cidadania e Constituição. Brasília, Revista da Ordem dos Advogados do Brasil, ano XXVII, nำ 65, jul./dez. 1997.

. Perspectivas do Direito Público Estudos em Homenagem a Miguel Seabra Fagundes. Belo Horizonte: Del Rey, 1995.

SALOMONI, Jorge Luis. Aporte para una Discusión sobre la Titularidad Estatal de los Servicios Públicos. Obra em homenagem ao Professor Miguel Marienhoff, Abeledo-Perrot, 1998.

- Teoria General de Los Servicios Públicos. Buenos Aires: AD-HOC, 1999.

. Reforma del Estado y Servicio Público: Titularidad y Privatización en el Derecho Público Argentino. Revista de Actualidad en el Derecho Público, Buenos Aires, n² 5, SCS \& Associados Editores, set./dez. 1996.

SIEYÈS, Emmanuel Joseph. A Constituinte Burguesa -O que éo Terceiro Estado? Rio de Janeiro: Liber Juris, 1988.

SilVA, Almirc do Couto e. Os Indivíduos e o Estado na Realização das Tarefas Públicas. Rio de Janei- to: Renovar, Revista de Direito Administrativo, n² 209, jul./set. 1997.

SILVA, José Afonso da. Aplicabilidade das Normas Constitucionais. 3. ed., São Paulo: Malheiros, 1999.

SOTO KLOSS, Eduardo. Derecho Administrativo Bases Fundamentales - El Principio de Juridicidad. Santiago do Chile, Editorial Jurídica de Chile, tomo II, 1996.

SOUTO, Marcos Juruena Villela Souto. Desestatização, Privatização, Concessões e Terceirizaçōes. Rio de Janeiro: Lumen Juris, 1997.

SUNDFELD, Carlos Ari. Fundamentos de Direito Público. 3. ed., São Paulo: Malheiros, 1997.

TÁCITO, Caio. Direito Administrativo Participativo. Rio de Janeiro: Renovar, Revista de Direito Administrativo, n² 209, jul./set. 1997.

TORRES, Luís Cláudio Alves. Manual de Legislação sobre Concessões de Serviços Públicos. Rio de Janeiro: Destaque, 1997.

VEDEL, Georges. Droit Administratif. 8. ed., 1977.

VIEIRA, Evaldo. Democracia e Política Social. São Paulo: Cortez, 1992.

ZANOBINI, Guido. Corso di Dinitio Amministrativo. Milão: Giuffrè, 1968. 